\title{
Sustainable Climate Approach and in Context of Environment Economy: A Classical Analyze Matters.
}

\author{
Sarmad Rahat, Muhammad Shoaib Khan Pathan \\ Department of Economics, Shah Abdul Latif University Khairpur Mir's, Sindh, Pakistan \\ sarmad.rahat@salu.edu.pk,m.shoaib@usms.edu.pk
}

\begin{abstract}
In the worldwide world, the climate has become a scant asset. Since the economy is tied in with adapting to asset shortage, the climate and the economy are interconnected. Then again, it is additionally evident that the economy, which types both confident and negative outwardness, effects the environment. Hence, it is unconceivable to imagine handling ecological issues from the out of the economy. Today, there are some monetary movements, for example, increasing use reliant on spending middles, city reestablishment, fast public growth, and so on one method of tackling the economy is to assurance that the expenditures and compensations of natural events are adjusted. While it is hard to appraise the expenditures and rewards, there is a developing interest for this to occur before monetary movement. Monetary and usual goals are frequently seen as opposing. It is putative that a choice must be made amongst one and the additional, and this can't be talented concurrently. To alteration this discernment, certain actions must be occupied at both the community and international levels. Now, a real usual review is important consistently to assurance a green economy. In this investigation, we drive look at what has been complete on the earth as to the green economy. In this specific circumstance, we will take a gander at what we need to do in Turkey as far as enactment.
\end{abstract}

Keywords:

Climate, economy , environment, environmental economics ,Sustainable climate

\section{Introduction:}

\subsection{The connection between the economy and the climate}

\subsubsection{Ideas of financial matters and climate}

The economy is a finished action that addresses human issues. However long the economy upholds these exercises, it should guarantee that the assets are utilized for limitless requirements. Since gentleman's supplies are boundless, however the work and crops that address those issues are in each circumstance scant and limited. Since the jumble amongst "supplies" and "produce benefits" that address these issues exists in shaped or young networks, industrialist or collectivist, this is known as the "rule of lack." And.pdf http://though the economy satisfies its fundamental capacity, which is to address human issues, it produces positive and negative externalities.

While the climate is a part that makes interest in the budget with its possessions, it is likewise the decency of outlines that are prejudiced by the negative outwardness of the reduced. In this manner, the cozy joining between the low-cost and the temperature prompts the budget dealing with the temperature, which has a limited basis.

As a rule, the climate is where human networks and different day to day routines sweat their lives and utilize regular assets. Distinctive ID for the climate resembles flows; The climate is the amount of physical, synthetic and social factors that straightforwardly or in a roundabout way influence human exercises and living things at some random time (Yrd.Doç.Dr.Murat ESMERAY and TANÇ 2009)

Regardless context-oriented climate it is utilized in, the idea of climate for the most part underlines "being in the middle and being outside the middle." Therefore, the not really set in stone rather than a middle and in this sense; it is an "outer" wonder (ÖZET 2017) 


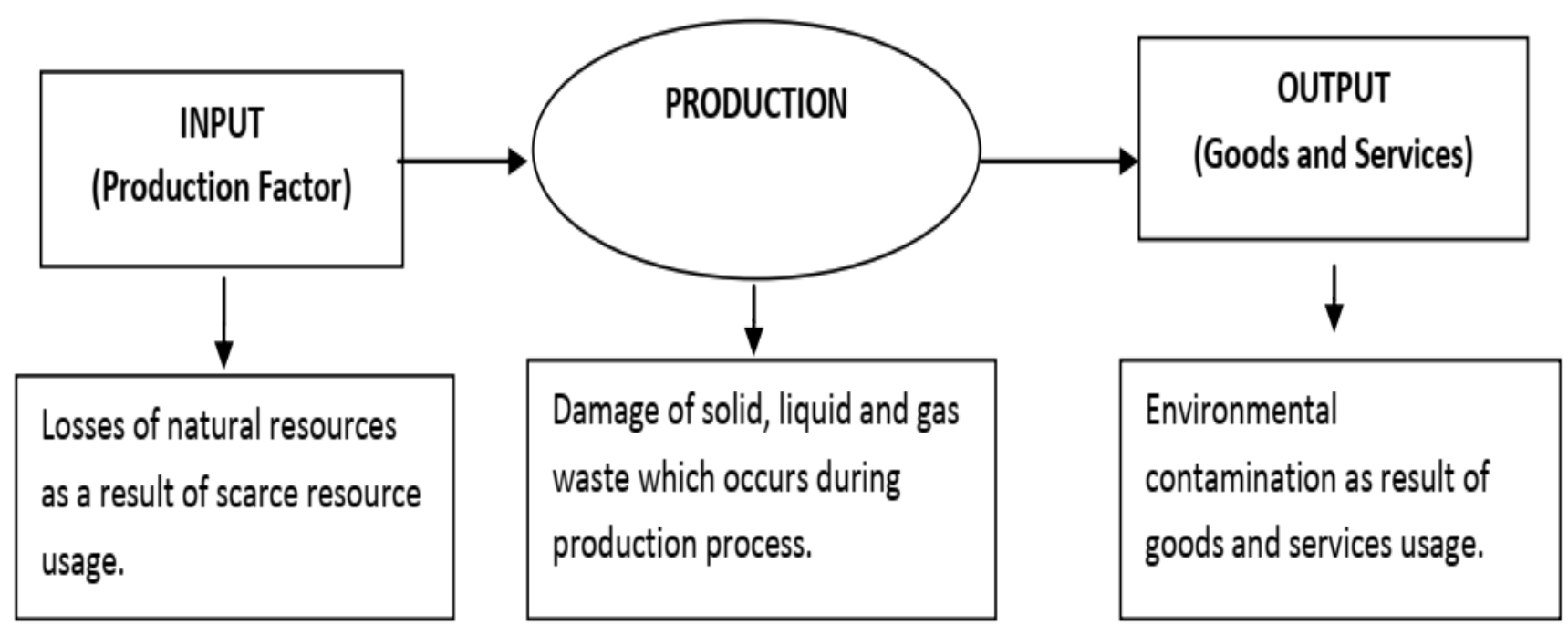

Figure 1: Business - Relationship of the regular habitat

Source by: (Yrd.Doç.Dr.Murat ESMERAY and TANÇ 2009), Işletme-Doğals’ Çevres’ Ilişkilerinins’ Mali Tablolars’ Aracılığıyla Raporlanması ve Denetimi, SPK Yayınları,P.31

Though the climate is an apparent outside wonder impacted through the formation of the conception series - work and harvests - it is additionally an incredible idea that joins fabricating issues - efforts. In this wisdom, the environment gives input information to the family and is impacted thru the outer components ended by the budget. Today, the two administrations and states are examining the boundless regular assets that the microclimate stretches as a commitment to the budget. Accordingly, ecological expenses are as of now being ready to limit both deliberate requests and legitimate arrangements.

In this sense, the green economy can be characterized as; "A particular subsector of the economy where ecological issues are seen according to a financial viewpoint, a promise to the budget with the safety of the weather and even possessions and the way contamination is limited.

Nowadays, contrasted with the past, the green economy has gotten progressively critical to guarantee the nonstop movement of the economy, completed by scant assets, and furthermore because of the wide idea of the climate, which remembers both the effect for the economy with its variables of creation and on the outside components of the economy. So; as Al-Yor, VP of the United States and furthermore a natural sub ject matter expert, says, "the ancient contention that the climate and the budget are in struggle is truly obsolete."

\subsection{The Antiquity of the Environmental Economics}

There are contrasts amid customary financial aspects and neoclassical ways to deal with financial aspects of natural issues. While in traditional financial aspects amount was thought of, in neoclassical financial aspects quality was additionally considered. As indicated by traditional market analysts like J.B. Say and Adam Smith, normal possessions are depicted as free products and are disallowed from monetary inspection. A. Pigu, a neoclassical business analyst, brought a natural idea into monetary investigation and along these lines established the framework for ecological financial matters.

A. Marshall is the main name that adds to the financial investigation of ecological issues. As per Marshall, market failures are at the foundation of the defilement. Also, Keynes, who was quite possibly the main financial experts in his last term, has made a stage for conversation right up 'til the present time about the outer elements of contamination that are or alternately are not addressed by market components (Yıldırım U.; Marin M. C. 2004)

\section{Natural Environmental Issues}

The natural expenses of the economy make ecological issues. There are excessively close and two-sided relations concerning monetary turn of proceedings and environmental issues. Fiscal progress is an aim, and biological issues are expected for its decision. The ecological issue normally incorporates every one of the disservices experienced in natural qualities (water, air, soil, and so on) because of human exercises. In this 
unique situation, the primary issue that rings a bell is a "contamination issue" (Yrd.Doç.Dr.Murat ESMERAY and TANÇ 2009)

Contamination is a debasement that harms the normal soundness of the climate and addresses catastrophic starts to live things since of filthy air, grimy aquatic and disordered waste transported about by the formation cycle to address human issues (ÖZET 2017)

There have been significant changes in the regular symmetry of setting and earth progression since of the use of fuel offshoots delivered into the air by ozone harming substances of the Industrial Revolution. So; "A dangerous atmospheric deviation" is another huge ecological issue that is the normal consequence of monetary exercises that discover an advertisement as a worldwide impression and are branded as "in the growth of normal fevers in the nations, loads and air noticed reliably".

\subsection{The Real Draw Backs of Environmental Pollutions}

Contamination is the idea of the natural issue. Albeit the reasons for contamination are presented to such countless variables, three primary titles are; Development and Mechanization Yrd.Doç.Dr.Murat ESMERAY and TANÇ (2009). Fact be told, these 3 fundamental titles have an association with one additional on a circumstances and logical results premise. For instance, expanding tension on the populace prompts unlawful movement and, in this unique circumstance, to city growth, so industrial development occurs to assurance monetary dynamism.

Nowadays, quick populace growth and since of development and the related urbanite alteration and development have expanded the environmental expenses of the budget. Exactly, with the explanations behind such municipal change projects and an alteration in client located practices, like spending middles, it was in development without the arrival of development structures, so ecological harm expanded at a similar degree or at the most elevated rate. It is likewise dicey that's the promise of these growths to the budget, aside from their ecological damage. Maybe probably the best illustration of this is; the enormous arenas worked for the 2014 FIFA World Cup in Brazil. It has been censured for its "utilization and delivery" the executives. In accordance with the development business in 2014, the Athens Olympics turned into a monetary downturn for Greece and its ecological harm.

\subsection{Ways to Deal with taking Care of Environmental Issues \\ 2.2.1. Public Methodologies}

The industrialized nations have effectively finished the course of industrialization, while the nonindustrial nations have picked the way of industrialization prior to completing a course of change from horticulture to manufacturing. Accordingly, this rapid and unrestrained mechanization has honest disapproving influences on the environment. together industrialized and agricultural nations, the economy is applying natural pressing factors, so lately the idea of climate has given need among the issues.

The best way to deal with tackling environmental issues is to position of these mechanisms that are causing the subject. This choice is everything except "reasonable"; it's essentially "revolutionary." Rational arrangements can be taken care of as; Sustainable turn of events, money saving advantage investigation, natural effect appraisal and different methodologies (Yrd.Doç.Dr.Murat ESMERAY and TANÇ 2009).

\subsubsection{Feasible Development - Sustainability}

The economy is at the core of "feasible turn of events" to dispose of the adverse consequence happening the climate. It is feasible to brand the depiction of "Economic Growth" as shadows; The arrangement of the present lifetime and the advancement of things to come through the foundation of a harmony among man and nature without hazard of harm to normal assets and the cognizant shielding of the utilization of assets. also, there is a wide agreement that's this implies that's monetary exercises must follow: the reasonable utilization of sustainable normal assets, the insurance of biological system qualities and capacities, preservation of organic variety, objective of contamination emanations underneath basic (digestion) limits and anticipation of irreversible harm to the climate and nature.

Supportability works both to limit the deficiency of ecological harm to the economy and to reuse that misfortune back into the economy. In this sense, nature-accommodating assembling innovations and the accessibility of proficient and useful advances will be required. In this way, the utilization of environmentally friendly power bases has become important in the regular part of the formation series to enhance to "natural maintainability".

Perhaps the best perfect has been Sverige in that the weather is being brought once more into the economy in the space of maintainable turn of events. Sweden's top of all nations for reusing, sun-oriented energy and significantly more economical practices and one nation keeps up with quite a bit of its requirement 
for warming from trash, begun bringing in squander from this is closest neighbor Norway. Truth be told, there are around eighty thousand tons of left-over smuggled from Norway.

In this intelligence, manageability is the idea that basically should be applied step by step to make a loop in the economy and stop the dynamic fixing of the climate. We additionally guarantee feasible turn of events, while our current circumstance can be switched. The natural financial aspects more on account of the ecological cognizance, the objective creates; "... to secure, to push ahead and to utilize it over and over

\subsubsection{Money Saving Advantage Examination}

Money saving advantage examination is a genuinely very much evolved technique for deciding the net return of the undertaking throughout a given timeframe. the lone change required is the consideration of ecological expenses or advantages. (Duta.m 2003)

To utilize money saving advantage investigation as a natural arrangement, the effects of the venture on the climate ought to be utilized as information. At the end of the day, it should be determined as a proportion by something the profit from cash and a beneficial outcome on the speculation, and as a denominator, thusly, by adding the outpourings and adverse consequences of the venture by the speculations made, and afterward concurring that the relationship to the denominator is the "money saving advantage proportion". By utilizing this proportion, both harmless to the ecosystem ventures and issues at the arranging stage can be kept away from.

Although cash surges (costs) can be determined somewhat comparable to natural harm, incomes can't be determined as far as sure effect on the climate. This makes the relevance of the methodology very troublesome (Yrd.Doç.Dr.Murat ESMERAY and TANÇ 2009).

Notwithstanding its known constraints, advantage and-cost investigation can be a vital method to reliably acclimatize heterogeneous data that is viable with acceptable dynamic. Whenever done right, it tends to be of extraordinary advantage to authorities as they attempt to lay out ecological objectives and goals.

\subsection{Natural Effect Appraisal}

The climate should be given a lawful reason for decreasing the pressing factor applied on it by industrialization. To increment both the financial advancement of nations and the nature of the climate, the "Ecological Impact Assessment" is a global idea that has discovered a spot.

An ecological effect appraisal is a methodology that dissects the impacts of a movement where it has an immediate or aberrant, positive or adverse consequence on the climate during its lively stage. It is moreover a way to contract with differentiate voting minimization arrangements that can be produced using the unfriendly impacts of the act. The report, recognized as the natural effect evaluation (EIA) approach, ought to be ready prior to settling on venture choices to forestall and recognize the possible ecological effect of the speculation. This is designated; "Natural Influence Valuation Account" or just as an EIA's account (Yrd.Doç.Dr.Murat ESMERAY and TANÇ 2009).

Although the way to deal with natural effect evaluation is like the other way to deal with taking care of ecological issues - the money saving advantage examination - in the direction of the positive and negative parts of natural speculations, it is a more complete methodology. Since it isn't compulsory with this way to deal with utilize the number for all information, it is additionally simpler to utilize (Yrd.Doç.Dr.Murat ESMERAY and TANÇ 2009).

\subsection{Environmental Law}

With this, the ubiquity of natural law has additionally kept on expanding under current conditions. The assurance and improvement of the climate, the foundation of rules, both to forestall contamination and to make up for harm, to make assets for this load of guidelines and to suggest sanctions, remain all inside the extent natural law.

\subsection{Government Strategy}

Contamination brought about by the bad outwardness of a budget can be addressed in a well-working evaluating outline. On the off accidental that a valuing outline is presented, cleaner innovations will be advanced, and the expenses of contamination will be genuinely conveyed.

However, even a well-working business sector framework can stay lethargic to decrease contamination. For reasons unknown, the assignment of the public economy as an answer for forestall contamination, which has the option to utilize monetary arrangement instruments and approaches, for example, charges and additionally endowments, is starting to fall. 


\subsection{Worldwide Regulations}

It is unavoidable to work for nations that tackle natural issues. Be that as it may, the work done all throughout the planet requires nearer participation between the gatherings and would, obviously, be seriously animating. This worldwide collaboration in the field of ecological insurance has been brought out through twofold or multilateral shows on global natural law.

In such manner, the main worldwide natural approach was presented as UNEP, trailed by a United Nations meeting in Stockholm in 1972.

Notwithstanding the Kyoto Protocol of 1997, a solitary structure for fighting an Earth-wide temperature boost and environmental change, which are one of the serious issues within recent memory, is likewise a significant worldwide ecological guideline.

All the while, which starts with UNEP and proceeds under the Kyoto Protocol, some significant arrangement alternatives have been distinguished, including lessening petroleum product utilization, creating environmentally friendly control bases to assurance the essential vigor and the effective use of liveliness. The consumption of new advances, and advances specifically, has-been additional plan choice to help states that have not yet over development events (Yıldırım U.; Marin M. C. 2004)

\section{Commitment to the Natural Appraisal of the Environmental Economics}

Record should likewise be taken of natural checking, which will add to the green economy. The fundamental component of ecological observing centers, obviously, on natural issues and means to work on the climate, which is both the current public assistance and the most significant of things to come for the entirety of mankind and guarantees practical use.

Starting here of view, the outer review part for the country, the Court of Auditors, has significant undertakings to act in surveying the utilization of a public source.

\subsection{Sorts of Natural Reviews}

Since it is realized that the administration of the arrangement of ecological issues was standard, which can be given both in public and worldwide laws and arrangements - Court of Auditors inside the structure of the assistance "Lawfulness Audit" for natural insurance and advancement. In this regard, the Court of Auditors can seek after consistence with global natural laws and deals as a community basis.

If the use of environmental possessions (air, aquatic, earth, and so on) and their effect on use are appropriately recorded, a "monetary review" on natural issues may likewise be conceivable.

With the "execution review" way, this is done through observing in natural projects, the ecological effect of different projects, ecological administration frameworks as well as ecological security arrangements. This has led to another idea called "4 E", which likewise incorporates cost-adequacy, effectiveness, proficiency and the climate as the reason for the "execution review".

\section{Conclusion}

Financial matters and climate were viewed as two unique ideas that supplant a similar level in trouble. It is putative that a choice must be made amongst one and the additional, and this can't be talented concurrently. Yet, the significance of public and worldwide work to change this methodology is developing.

In this sense, security should be made, in view of economies dependent on the ecological field, both at public and worldwide level. Furthermore, financial approaches should be produced that don't think about ecological issues as a characteristic outcome of monetary exercises and that consider the climate and its worth.

Positive two-sided relations between the economy and the climate can be guaranteed through manageable turn of events. It should in this manner target naturally strong economies: eco-impacts. Therefore, clean, natureaccommodating innovations are liked, and in case toxins are yet present, they should be reused.

Additional highlight brand well known naturally practical economies (eco financial matters) is that; Economists and preservationists. Just financial specialists and preservationists cooperating can expand on their future today (Yıldırım U.; Marin M. C. 2004)

Notwithstanding the manageable advancement approach, the money saving advantage investigation approach ought to be utilized to foster a compelling natural arrangement dependent on the negative externalities of financial exercises.

Be that as it may, while populace development influences urbanization and industrialization, just as nations' monetary and ecological issues, it additionally causes an increment in worldwide natural issues. Hence, it is; Perhaps the strategy of populace control ought to develop all throughout the planet to act as an illustration of the present China. As per Violence; The biosphere is relied upon to consume more than nine million individuals by 2085, and quite a bit of this development comes from agricultural nations in Africa. So; Geer 
contends that "fruitfulness the board" is expected to address a scope of worldwide improvement issues, including environment activity.

Likewise, ecological harm is brought about by urbanization and designs brought about by the normal result of populace development and inside relocation. Hence, to diminish the effect of ecological harm, a sound and adjusted urbanization strategy should be set up, and this arrangement should be carried out by guaranteeing maintainability. The entire of the upcoming, nationals, existing creatures and the temperature should be careful (AKYEL R. 2013)

One of the primary details that lead to environmental subjects is that proficiency isn't given the meaning happening and utilization movements, fair as in the allotment of assets and the utilization of advancements. Innovation in this manner assists non-industrial nations with zeroing in on a proposed arrangement.

Ecological observing must likewise be viewed as a successful device for tackling natural issues and in this manner requires the collaboration of more than one of the gatherings under the watchful eye of the Law court of Auditors

Moreover, the significance of carrying out a data and moderate natural arrangement is verifiable. While natural guidelines make an optimistic commitment to the budget by making new commercial rates, they can likewise be an impetus for nations to guarantee communication between the economy and the climate. What's more, once more, says Al-Eur; "We can work on our economy and make a huge number of good new positions in the event that we foster new innovations that can assist us with tidying up the climate

\section{References}

AKYEL R. 2013. "The President of Turkish Court of Accounts." 41.

Duta.m. 2003. "New Economic Dimensions in Economic Thought: The Case of Environmental Economics." Journal of the Alumni Association of the Economics Department Calcutta University 95-109.

ÖZET. 2017. 'Bir 'İnsan Hakki' Olarak 'Çevre Hakki' Ve Türk Hukukundaki Yeri Environmental Rights As Human Rights And Its Place In Turkish Law.” International Journal Of Political Studies 3(1):1-20.

Yıldırım U.; Marin M. C. 2004. "Çevre Sorunlarına Çağdaş Yaklaşımlar, Beta Yayınları."

Yrd.Doç.Dr.Murat ESMERAY, and Arş. Gör. Şükra. GÜNGÖR TANÇ. 2009. "Çevresel Maliyetlerin Mamullere Yüklenmesinde Kullanilan Dağitim Anahtarlarinin Seçiminde Analitik Hiyerarşi Yöntemi Ve Bir Uygulama.” 14(2). 